\title{
GALERI WISATA-MAKNA FOTOGRAFI
}

\author{
Gerald $^{1)}$, Alvin Hadiwono ${ }^{2)}$ \\ 1) Program Studi S1 Arsitektur, Fakultas Teknik, Universitas Tarumanagara, Gerald.tanujaya@yahoo.com \\ 2) Program Studi S1 Arsitektur, Fakultas Teknik, Universitas Tarumanagara, Alvinhadiwono@ymail.com
}

\begin{abstract}
Abstrak
Penulisan Laporan kali ini bertujuan menginformasikan tentang sebuah seni dalam perkembangan teknologi yang sangat pesat di era globalisasi saat ini yaitu fotografi, hampir diseluruh dunia yang serba digital kali ini fotografi mengambil peran penting di berbagai aspek kehidupan dan dapat menjadi sebuah jembatan antar bahasa bagi seluruh dunia, sehingga sangat bersinergi dengan media informasi dan platform media sosial yang sangat marak di era digital dan market place online. Fotografi memiliki perkembangan yang cukup pesat dan dampak yang sangat besar salah satunya dalam aspek pariwisata architourism. banyaknya eksistensi perlombaan fotografi sebagai salah satu cara marketing di era digital ini, dan juga daya beli kamera yang terus meningkat menunjukan bahwa Indonesia menerima dengan baik teknologi fotografi itu sendiri, berkaca dari kemajuan bidang fotografi yang pesat, khususnya di kota metropolitan Jakarta yang menjadikan titik acuan prospek strategis untuk menampung kegiatan praktik fotografi yang sangat kompleks dan cukup dapat mewarnai atmosfer dunia seni, pendidikan, perdagangan konvensional dan digital, parawisata, dan media lain dituangkan ke dalam suatu wadah galeri fotografi.
\end{abstract}

Kata kunci: Architourism, Digital, Fotografi, Galeri, Seni.

\begin{abstract}
Writing This report aims to inform about an art in technological development that is very rapid in the current era of globalization, especially photography, it takes an important role in various aspects of life and can become a bridge between languages for the whole world, so that it is very synergized with information media and social media platforms that are very prevalent in the digital era and online market place. Photography has a fairly rapid development and a huge impact is one of them in the aspect of architourism tourism. the existence of many photography events as one of the ways of marketing in this digital era, and also the increasing purchase power of cameras shows that Indonesia receives well the technology of photography itself, reflecting the rapid progress of photography, especially in the metropolitan city of Jakarta which makes reference points of strategic prospects for accommodating photography practice activities that are very complex and sufficient to color the atmosphere of the world of art, education, conventional and digital commerce, tourism, and other media are poured into a photography gallery building.
\end{abstract}

Keywords: Architourism, Art, Digital, Gallery, Photography

\section{PENDAHULUAN}

Perkembangan teknologi yang sangat pesat di era globalisasi saat ini telah memberikan banyak manfaat dalam kemajuan diberbagai aspek kehidupan di seluruh dunia. Berbagai macam tipe pengunaan teknologi oleh manusia dimanfaatkan dalam membantu menyelesaikan berbagai macam pekerjaan yang merupakan hal yang menjadi keharusan dalam kehidupan.

Salah satu teknologi yang berkembang pesat adalah fotografi, hampir diseluruh dunia yang serba digital ini fotografi mengambil peran penting di berbagai aspek kehidupan dan dapat menjadi sebuah jembatan antar bahasa seluruh dunia, sehingga dapat bersinergi dengan media informasi dan platform media sosial yang sangat marak di era digital ini. Berkaca dari kemajuan bidang fotografi yang pesat, khususnya di kota metropolitan Jakarta yang menjadi 
titik acuan prospek strategis untuk menampung kegiatan praktik fotografi yang sangat kompleks dan cukup dapat mewarnai atmosfer dunia seni, pendidikan, perdagangan konvensional dan digital, parawisata, dan media lain dituangkan ke dalam suatu wadah galeri fotografi.

\section{METODE}

Metode perancangan yang digunakan berupa metode kualitatif melalui literatur buku dan media elektronik dalam mengumpulkan data. Selain itu survey lapangan dilakukan terhadap tapak eksisting dengan hubungannya antara kondisi kawasan di sekitar tapak.

\section{DISKUSI DAN HASIL}

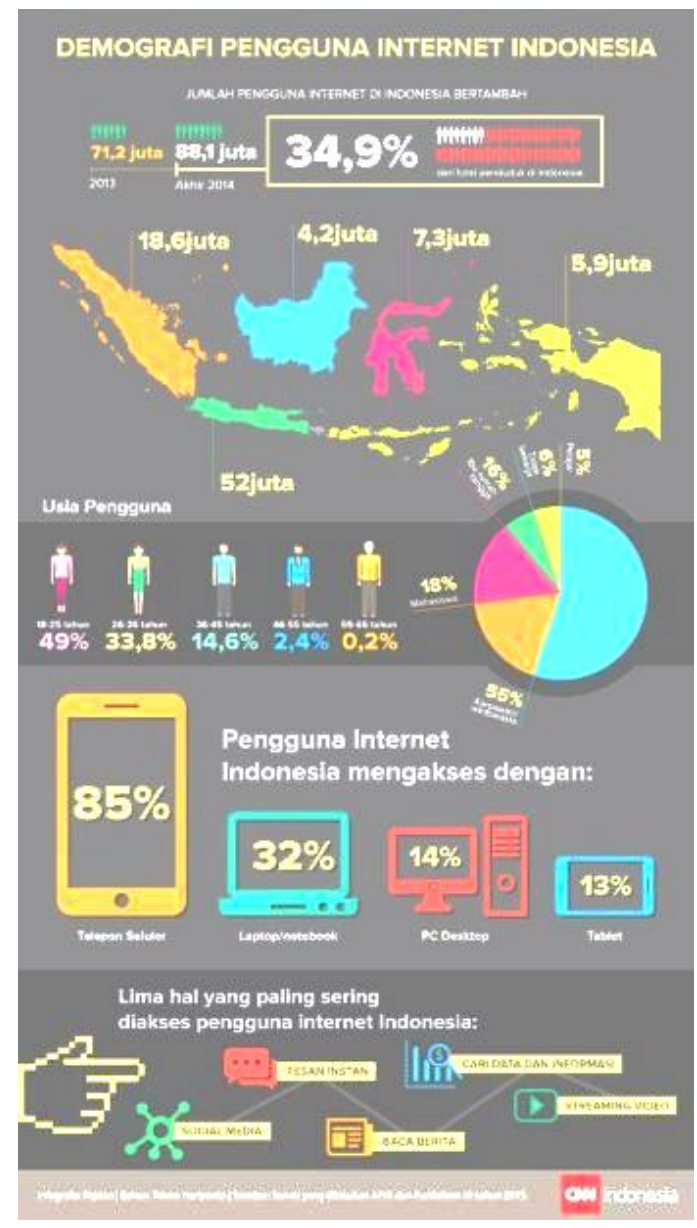

Gambar 1. Demografi Pengguna Internet Sumber: CNN Indo, 2018

Era digital saat ini tidak luput dalam penggunaan internet, menurut gambar 1 pengguna internet di indonesia sangat banyak jumlahnya dalam hitungan perhari, salah satu konten yang paling banyak dilihat adalah media visual 2D yaitu fotografi. 


\section{Produsen kamera ramai-ramai incar pasar mirrorless}

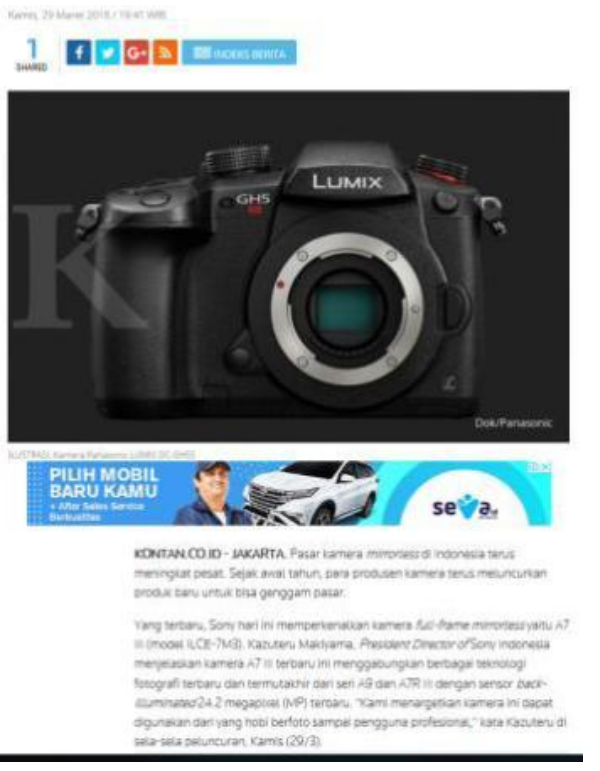

Gambar 2. Produsen Kamera Mirorless Ramai Sumber: Industri Kontan, 2018

Data berikutnya yang didapat adalah data maraknya penjualan kamera digital di penghujung tahun 2018, data ini mencerminkan bahwa banyaknya peminat fotografi baik dalam bidang amatir maupun profesional.

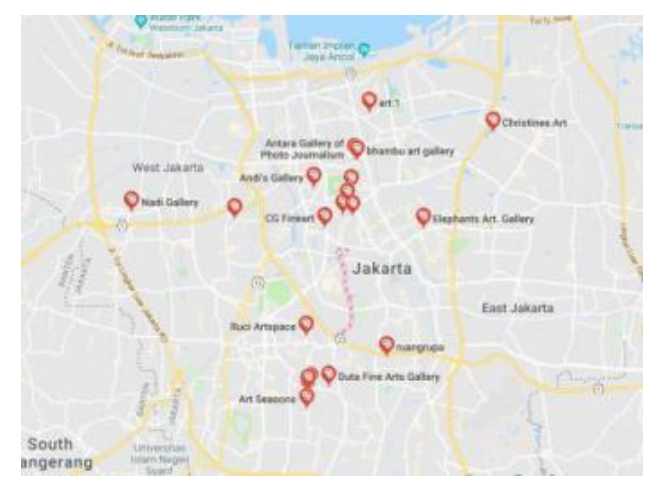

Gambar 3. Penyebaran Art Space Jakarta

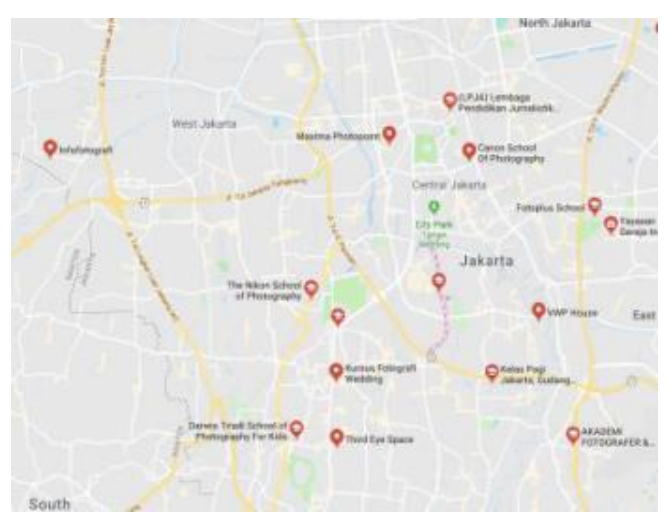

Gambar 4. Penyebaran Sekolah Fotografi 


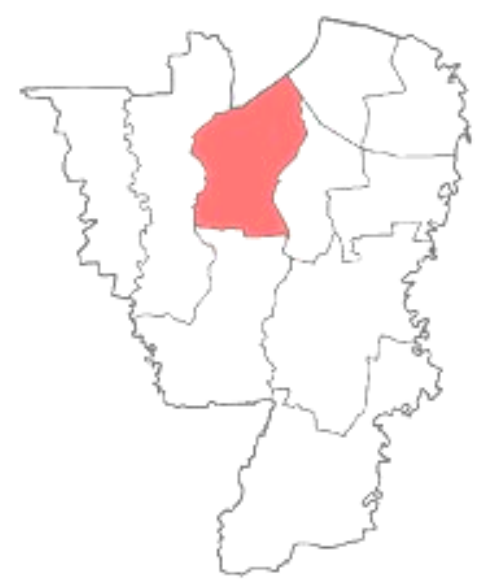

Gambar 5. Peta Jakarta Selatan

Daerah Jakarta Selatan memiliki potensi yang sangat kuat untuk mendirikan sebuah wadah komunitas dan galeri fotografi karena dikelilingi dominan oleh galeri seni dan sekolah fotografi.

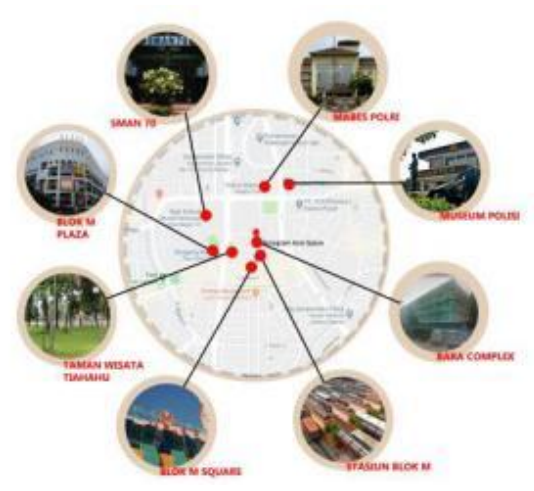

Gambar 6. Bangunan Sekitar

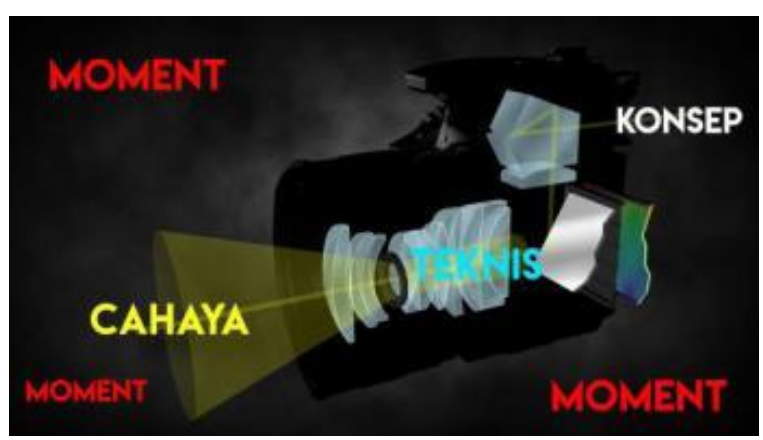

Gambar 7. Konsep Kamera

Adalah konsep perjalanan kedalam sebuah kamera, dimana jikalau kamera menangkap cahaya, bangunan ini menangkap manusia sehingga tertarik masuk ke dalam bangunan, namun secara arsitektural, bangunan ini memiliki keterbukaan yang tinggi untuk menerima natural light untuk masuk kedalam bangunan. Konsep yang diterapkan pada fasad dan massa bangunan merupakan metafora dari sebuah pemahaman filsafat tentang momen, yaitu da-sein (real) dan mit-sein (unreal, nostalgic), sehingga massa bangunan dipecah menjadi 2 sehingga mencerminkan ke dua paham dalam momen itu sendiri 


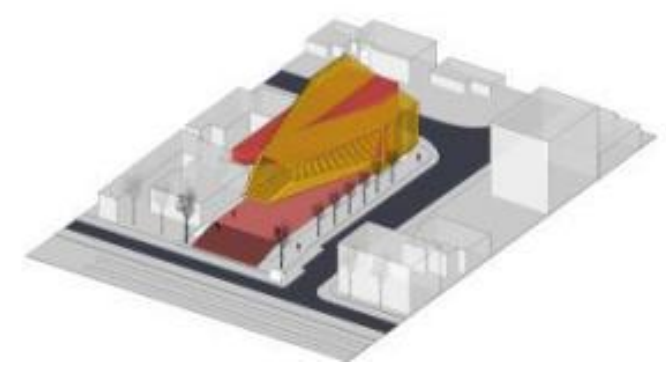

Gambar 8. Tahap Massing Dasein Mitsein

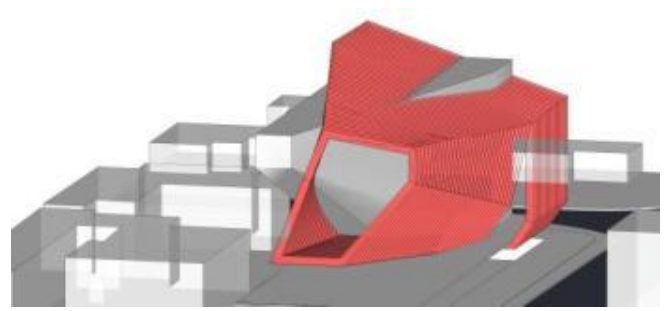

Gambar 9. Fasad Mitsein Bangunan

Fasad kisi kisi pada bangunan ini mengadaptasi dari sebuah elemen dalam kamera yaitu diafragma kamera dimana berfungsi untuk menangkap banyaknya cahaya yang masuk, pada bangunan ini adalah metafora untuk menarik perhatian manusia untuk menangkap manusia tertarik memasuki bangunan galeri ini.

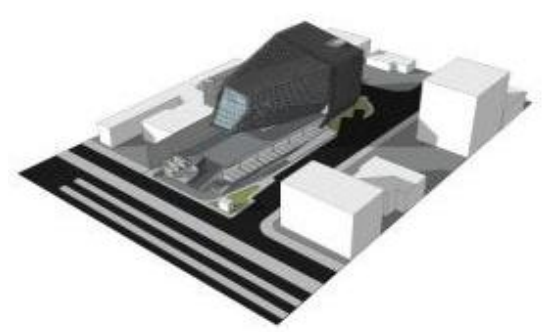

Gambar 10. 3D Final Bangunan

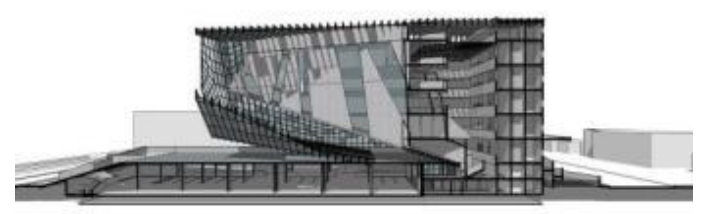

Gambar 11. Potongan 3D Bangunan

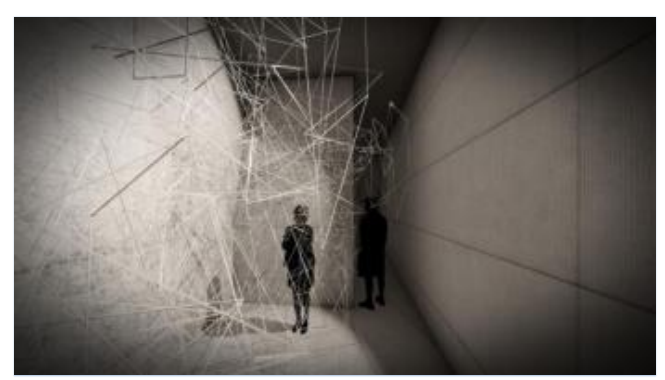

Gambar 12. 3D Interior Bangunan 


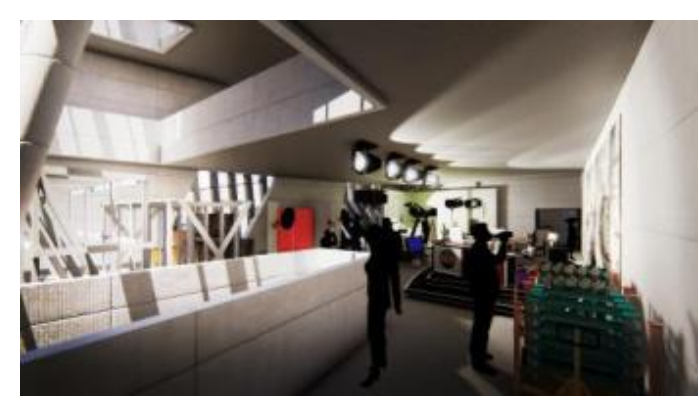

Gambar 13. 3D Interior Bangunan

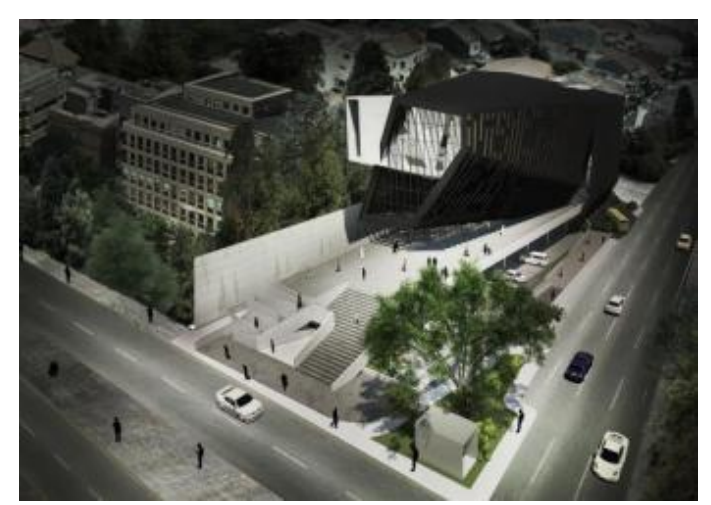

Gambar 14. 3D Exterior Bangunan

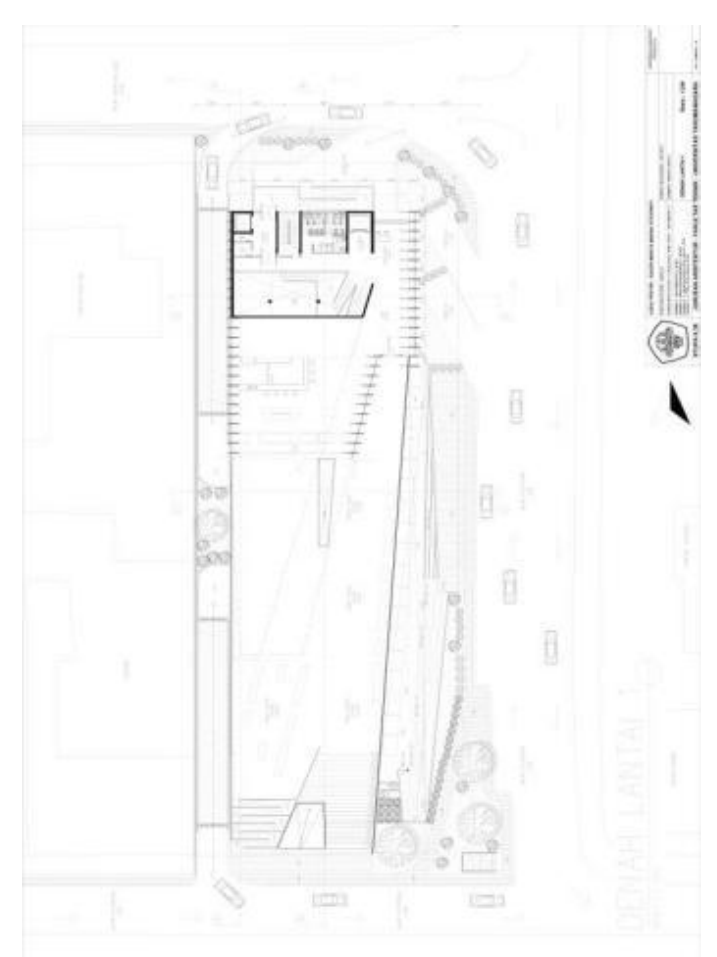

Gambar 15. Denah Lantai 1

\section{KESIMPULAN DAN SARAN}

Galeri Wisata-Makna Fotografi menjadi bangunan yang tepat dalam konteks architourism di metropolis kota jakarta, bangunan ini dapat menjadi tujuan wisata yang ikonik dalam jenis wisata baru, bangunan ini juga dapat membantu menggerakan roda perokonomian daerah, dapat menarik wisatawan secara umum maupun profesional dalam kegiatan praktik fotografi ini. Bangunan ini memiliki konsep yang kental terhadap filosofi fotografi sehingga dapat 
menjadi bangunan yang mengedukasi dan memberikan interaksi terhadap pengguna bangunan ini, diharapkan bangunan ini dapat meningkatkan kesadaran dalam pengapresiasian seni terutama fotografi dan juga menghargai lebih para penggiat komoditi fotografi.

\section{REFERENSI}

Jan Specht. (2011). Architectural Tourism Building for Urban Travel Destination. Munich.

Springer Gabler.

Seno Gumira. (2003). Kisah Mata.

F. Budi Hardiman. (2008). Heidegger dan Mistik Keseharian: Suatu Pengantar Menuju Sein und Zeit.

James Thurber. (1939). The Secret Life of Walter Mitty.

Ernst Neufert. (1939). Architect's Data.

Brian McLaren. (2004). Architecture and Tourism: Perception, Performance and Place.

Bruce Hayllar. (2008). City Spaces Tourist Places.

Vilém Flusser. (1983). Towards a philosophy of photography

Paparan Deputi BPDIP, Pembangunan destinasi pariwisata prioritas 2016-2019

https://www.theguardian.com/artand design/2017/oct/01/bilbao-effect-frankgehry-

guggenheim-global-craze

Jatim Kemenag, Teknik dasar fotografi

http://jatim.kemenag.go.id/file/file/teknikdasarpotograpi/bzhj1395972964.pdf

https://www.youtube.com/watch?v=dvd18-s8_ys

https://hot.detik.com/art/d-4030860/karya-yayoi-kusama-dirusak-pengunjung-di-museum-

macan-jakarta-ada-apa

https://ulinbareng.wordpress.com/2016/08/25/jenis-jenis-wisata/

http://febryaristian.blogspot.com/2011/12/tentang-kota-metropolitan.html

http://euforia-again.blogspot.com/2012/10/kota-metropolitan.html

http://abstrak.ta.uns.ac.id/wisuda/upload/C0809033_bab1.pdf

http://eprints.undip.ac.id/42307/1/Document1.pdf

https://www.msn.com/id-id/berita/teknologidansains/kamera-mirrorless-gantikan-dslr/ar-

BBJp4IU

http://abstrak.ta.uns.ac.id/wisuda/upload/C0809033_bab1.pdf

https://issuu.com/rujak/docs/zonasi_dki_jakarta

https://id.wikipedia.org/wiki/Terminal_Blok_M,_Jakarta

https://malesbanget.com/2016/03/jakarta-utara-jakarta-selatan-kamu-jagoin-yang-

mana/?utm_source=citizen6\&utm_medium=read-more\&utm_campaign=distribution-

partner

https://app.kompas.com/tekno/read/2017/07/20/16031737/2017-canon-ingin-jual-100.000-

kamera-saku-di-indonesia

https://industri.kontan.co.id/news/produsen-kamera-ramai-ramai-incar-pasar-mirrorless

https://www.archdaily.com/890404/jan-shrem-and-maria-manetti-shrem-museum-of-art-so-il

https://www.archdaily.com/24773/pullpo-advertising-agency-hania-stambuk

https://www.archdaily.com/452166/kolkata-museum-of-modern-art-herzog-and-de-meuron

https://www.archdaily.com/777820/ksp-jurgen-engel-wins-competition-for-new-shenzhen-

art-museum-and-library

https://www.archdaily.com/52446/nanjing-art-museum-ksp-jurgen-engel-

architekten?ad_medium=widget\&ad_name=more-from-office-article-show

https://www.dezeen.com/2018/07/14/femme-atelier-ombre-furniture-design/ 